\title{
Philosophiques
}

\section{Livres reçus (printemps 2004)}

Volume 31, numéro 1, printemps 2004

Poincaré et la théorie de la connaissance

URI : https://id.erudit.org/iderudit/008954ar

DOI : https://doi.org/10.7202/008954ar

Aller au sommaire du numéro

Éditeur(s)

Société de philosophie du Québec

ISSN

0316-2923 (imprimé)

1492-1391 (numérique)

Découvrir la revue

Citer ce document

(2004). Livres reçus (printemps 2004). Philosophiques, 31(1), 289-289.

https://doi.org/10.7202/008954ar

Ce document est protégé par la loi sur le droit d'auteur. L'utilisation des services d'Érudit (y compris la reproduction) est assujettie à sa politique d'utilisation que vous pouvez consulter en ligne.

https://apropos.erudit.org/fr/usagers/politique-dutilisation/
Cet article est diffusé et préservé par Érudit.

Érudit est un consortium interuniversitaire sans but lucratif composé de l’Université de Montréal, l'Université Laval et l'Université du Québec à Montréal. Il a pour mission la promotion et la valorisation de la recherche. https://www.erudit.org/fr/ 


\section{Livres reçus (printemps 2004)}

Bernays, Paul, Philosophie des mathématiques, introduction et traduction de H. Benis Sinaceur, Paris, Vrin (collection Mathesis), 2003, 236 pages.

Charles, Sébastien, Berkeley au siècle des lumières. Immatérialisme et scepticisme au XVIII $^{e}$ siècle, Paris, Vrin (collection: Bibliothèque d'histoire de la philosophie), 2003, 370 pages.

Dauvois, Nathalie et Grosperrin, Jean-Philippe (dis.), Songes et songeurs (XIII ${ }^{e}-$ XVIII ${ }^{e}$ siècle), Québec, Presses de l'Université Laval, (Les collections de la République des lettres), 2003, 253 pages.

Duhamel, André, Une éthique sans point de vue moral. La pensée éthique de Bernard Williams, Québec, Presses de l'Université Laval (collection: Mercure du nord), 2003, 195 pages.

Fisette, Denis et Poirier, Pierre (dir.), Philosophie de l'esprit I. Psychologie du sens commun et sciences de l'esprit, Paris, Vrin, 2002, 382 pages.

Gascoigne, Neil, Scepticism, Montréal et Kingston, McGill-Queen's University Press (collection: Central problems of philosophy), 2002, 218 pages.

Gosseries, Axel, Penser la justice entre les générations. De l'affaire Perruche à la réforme des retraites, Paris, Flammarion (collection: Alto), 320 pages.

Husserl, Edmund, La représentation vide suivi de Les Recherches logiques, une œuvre de percée sous la direction de Jocelyn Benoist et Jean-François Courtine, Paris, Presses Universitaires de France (Collection Épiméthée), 2003, 305 pages.

Ipperciel, Donald, Habermas: le penseur engagé. Pour une lecture "politique» de son cuvre, Québec, Presses de l'Université Laval (collection: Lectures), 2003, 75 pages.

Kervégan, Jean-François et Gilles Marmasse (dir.), Hegel penseur du droit, Paris, CNRS Editions, 2004, 300 pages.

Libera, Alain de, La référence vide. Théories de la proposition, Paris, Presses Universitaires de France, 2002, 358 pages.

Ludwig, Kirk (éd.), Donald Davidson, Cambridge et New York, Cambridge University Press, 2003, 240 pages.

Malinowski-Charles, Syliane (dir.), Figures du sentiment: morale, politique et esthétique à l'époque moderne, Québec, Presses de l'Université Laval (Les collections de la République des lettres), 2003, 175 pages.

Ménage, Gilles, Histoire des femmes philosophes, traduit du latin par Manuella Vaney et présenté par Claude Tarrène, Paris, Arléa (collection: Retour aux grands textes), 2003, 91 pages.

Ogien, Ruwen, Le rasoir de Kant et autres essais de philosophie pratique, Paris, Editions de l'Eclat (collection: Tiré à part), 2003, 222 pages.

Ouellet, Pierre (dir.), Le soi et l'autre. L'énonciation de l'identité dans les contextes interculturels, Québec, Presses de l'Université Laval (collection: Interculture), 2003, 446 pages.

Philosophy Students' Association of McGill, Pensées. Canadian Undergraduate Journal of Philosophy/Revue étudiante canadienne de philosophie, vol. 4, 2003, 82 pages. 
Romanian Society for Phenomenology, Studia Phaenomenologica. Romanian Journal for Phenomenology: the School of Brentano and Husserlian Phenomenology, vol. III, n ${ }^{\text {os }} 1-2,2003,307$ pages.

Tanguay, Daniel, Leo Strauss. Une biographie intellectuelle, Paris, Grasset (collection: Le collège de philosophie), 2003, 335 pages.

Thomas, Chantal, Souffrir, Paris, Editions Payot et Rivages, 2004, 218 pages.

Zambrano, Maria, Philosophie et poésie, traduit de l'espagnol par J. Ancet, Paris, José Corti, 2003, 172 pages.

Zambrano, Maria, Les rêves et le temps, traduit de l'espagnol par G. Flores et A. Louis, Paris, José Corti, 2003, 245 pages.

Outre les ouvrages qui apparaissent dans cette liste, la rédaction de Philosophiques peut obtenir, pour des comptes rendus ou études critiques, la plupart des livres parus récemment.

Les personnes désireuses de faire un compte rendu sont priées de s'adresser à :

Jimmy Plourde Département de philosophie Université du Québec à Montréal C.P. 8888 , Succ. Centre-ville Montréal, H3C 3P8 Courriel : jimmy.plourde@uqam.ca 